\title{
Does medical professionalism have a dark side?
}

\author{
Cite as: CMAJ 2020 November 30;192:E1646-7. doi: 10.1503/cmaj.1095907
}

Posted on cmajnews.com on November 13, 2020

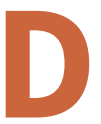

octors pride themselves on being professional. But some warn that codes of conduct and dress can reflect and reinforce biases that disadvantage equity-seeking groups and those who challenge the status quo in medicine.

Earlier this year, a study of social media behaviour among young vascular surgeons was roundly criticized within the profession for labelling doctors who wear bikinis, drink alcohol, or post political or religious comments as "unprofessional."

Ultimately, the Journal of Vascular Surgery retracted the article. In an apology letter, the journal's editors acknowledged, "professionalism has historically been defined by and for white, heterosexual men and does not always speak to the diversity of our workforce or our patients."

Since then, a growing number of doctors have spoken out about the pressure they feel to stay silent about racism, follow "white" norms of dress and expression, and conceal their culture or religion to appear professional.

Dr. Jennifer She, a resident in psychiatry at the University of Toronto, says early lessons on professionalism in her undergraduate medical training emphasized different rules for women than men.

"There was a lot on what women should and shouldn't wear," She says. "Your collar shouldn't be too low. You should be covering your shoulders." By contrast, "there were two lines on what men should and shouldn't wear, including a debate about when ties are permitted because, although they look professional, there can be hygiene issues."

Recent studies have shown that senior physicians and colleagues judge women more harshly than men for making the same errors in medical training and practice. Senior physicians are also more likely to evaluate women and racialized trainees

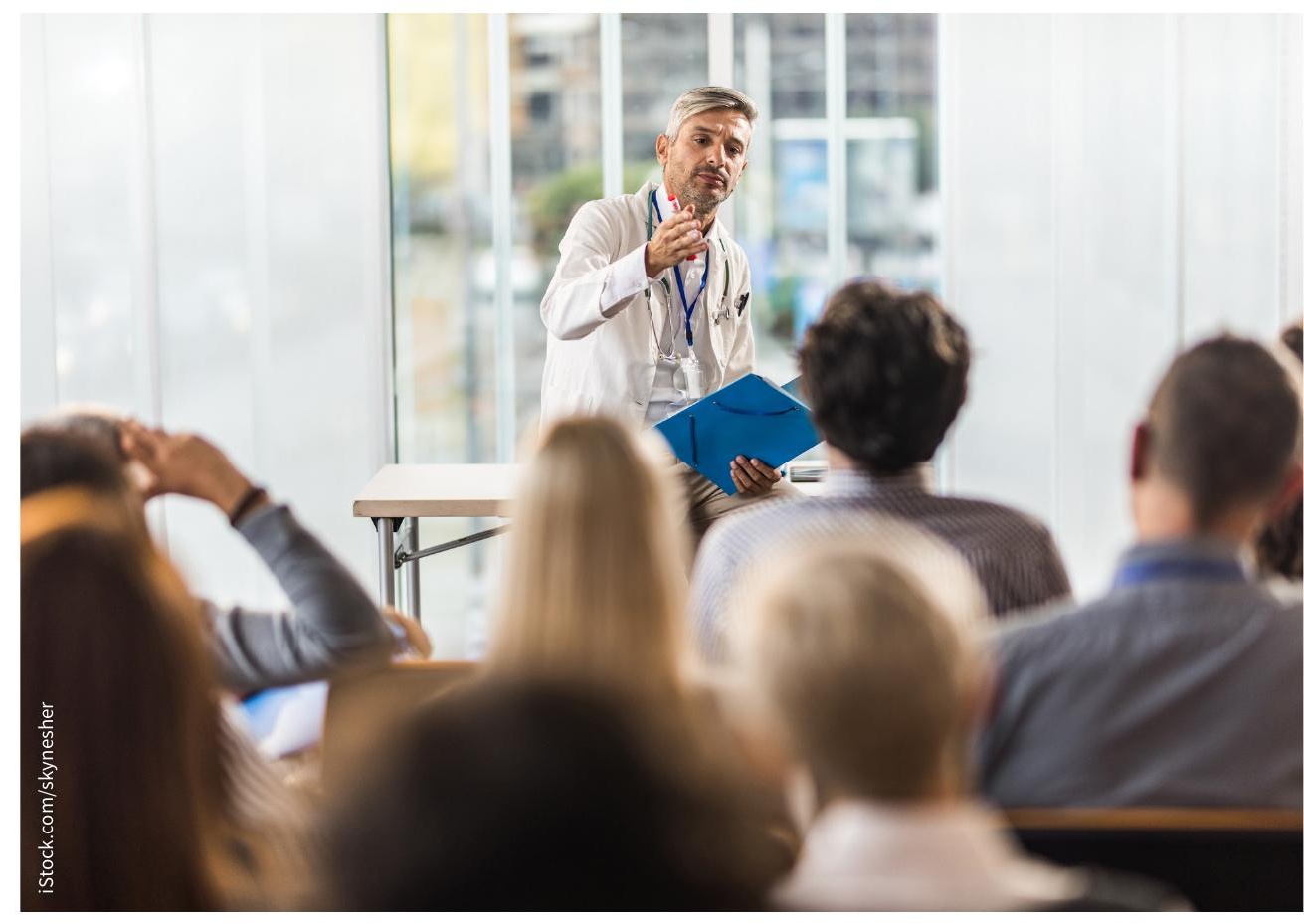

Unexamined biases in medical professional standards may disadvantage those who don't fit the stock photo image of a doctor.

based on personal attributes than competence and more frequently describe white trainees using exceptional terms.

Medical trainees who run afoul of the rules risk receiving a "professionalism red flag" on their permanent record, which can make it difficult or even impossible to get a residency position, she says. Yet, codes of conduct and dress can be vague and open to interpretation, leading to inconsistent application. For example, the McGill University dress code advises trainees to wear footwear that is "professional and comfortable" such as "not too flashy" sneakers.

She says many medical learners "especially those of us from marginalized backgrounds" - avoid complaining, including about working conditions, for fear of being labelled unprofessional. But in other cases, bad behaviour appears to escape accountability.

She attributes the problem to a lack of diversity among those setting and enforcing professional standards. Medical leadership is dominated by white, cisgendered men, although gender balance is improving in some areas. "If people in leadership continue to look the way that they do, then the people who are being protected will continue to look the way that they do," She says.

Suffia Malik, a medical student at Queen's University, says people from underrepresented groups often worry that they are perceived as unprofessional by default. Starting with medical school interviews, would-be doctors debate 
whether to downplay aspects of their identity, Malik says. "People will ask, 'Do I wear my hijab in a different style that would be more palatable?' When beards were less fashionable, Muslim men would ask, 'Will the panel think negatively of me if I show up with my full beard?'”

According to Dr. Pier Bryden, senior advisor for clinical affairs and professional values at the University of Toronto's faculty of medicine, medical schools across Canada are rethinking how they define and enforce professionalism.

Bryden says it's still useful to have shared values and expectations for behaviour. "To not have that would feel unsafe," she says. However, "we need to make sure that notion isn't used in a way that contributes to the oppression of equity-seeking groups."

Bryden says it's critical to ensure that unprofessional behaviour is clearly defined and recourse is transparent and easily accessible, "so that people can very much expect the same approach."

The University of Toronto revised its standards of professional behaviour for medical faculty in the spring. "We clearly highlighted the importance of wellness, allyship, understanding and awareness of the Truth and Reconciliation Commission calls to action, and the importance of a culturally safe and psychologically safe environment for collegiality and education," Bryden says.

Of course, changes on paper aren't enough. "You have to build a whole culture around that, and that's harder," Bryden says. To reinforce the new standards, Bryden and her team rolled out professional development materials for medical faculty, including an interactive module on responding to discriminatory behaviour.

In medical training and beyond, the notion that professionals don't rock the boat can pose a barrier to reform. Recently, physicians have faced formal complaints about the professionalism of calling out colleagues or sharing political views online.

Dr. Nav Persaud of St. Michael's Hospital in Toronto says that questioning the status quo can be "interpreted as a criticism of the profession in general, or some of your colleagues in particular, even if the goal is to improve care for patients."

For example, Persaud notes that when he raised concerns about doctors receiving payments to promote opioids, some colleagues questioned the professionalism of his advocacy "without questioning the professionalism of those engaged in the misconduct."

In some cases, it can feel like there is no right way to advocate for change. "People question things like why you decided to have a meeting instead of sending an email, or why you decided to send an email instead of meeting," Persaud says.

Dr. Amit Arya says he often sees people in authority focus on "the tone of what's being said" rather than the substance, particularly when the message comes from women or racialized people.

Yet, Arya also sees growing acceptance of physician advocacy as more doctors "move into the political sphere" in response to government failures during the pandemic. Arya says it's a marked difference from his experiences during training when he was told that advocacy about issues like housing and food security "is not our job."

Now, he wonders if the medical community should place less emphasis on professionalism. Instead, new codes could "promote critical thought and innovation, highlighting people's voices who need to be heard."

Wendy Glauser, Toronto, Ont. 